\title{
Globe
}

Revue internationale d'études québécoises

\section{Naïm Kattan : L'écrivain migrant. Essais sur des cités et des hommes. Montréal, Hurtubise HMH, coll. « Constantes ", 2001}

\section{Sophie Marcotte}

Volume 5, numéro 2, 2002

URI : https://id.erudit.org/iderudit/1000686ar

DOI : https://doi.org/10.7202/1000686ar

Aller au sommaire du numéro

Éditeur(s)

Globe, Revue internationale d'études québécoises

ISSN

1481-5869 (imprimé)

1923-8231 (numérique)

Découvrir la revue

Citer ce compte rendu

Marcotte, S. (2002). Compte rendu de [Naïm Kattan : L'écrivain migrant. Essais sur des cités et des hommes. Montréal, Hurtubise HMH, coll. "Constantes ", 2001]. Globe, 5(2), 182-183. https://doi.org/10.7202/1000686ar d'utilisation que vous pouvez consulter en ligne.

https://apropos.erudit.org/fr/usagers/politique-dutilisation/ 
analyse des identités en mouvement à partir de trois zones limitrophes des Amériques. Quant à Marc Gontard, il suit un cheminement sémiologique lorsqu'il se transporte en Orient pour étudier Madame Chrysanthème, de Pierre Loti et René Leys, de Victor Segalen, dans son essai " Le désir de l'autre : pour une sémiotique du regard exotique .

Dans un troisième cas, des assises d'ordre géographique soutiennent les travaux : Sébastien Joachim propose ainsi de voir l'espace canadien en tant que scène de l'altérité et Rachel Bouvet expose, par la lecture de The Sheltering Sky de.Paul Bowles, comment l'espace du désert acquiert une valeur symbolique. Enfin, le dernier essai, "Lectures divergentes: Les nouvelles expériences de la textualité ", signé par Bertrand Gervais, aborde le thème de la communication à l'ère de l'internet. Nous ne pouvons que féliciter l'Université d'État de Feira de Santana, ainsi que Humberto de Oliveira, Danielle Forget et l'Association brésilienne d'études canadiennes (ABECAN), pour ce livre, si riche en points de vue et en pistes pour le lecteur avide de pénétrer dans la culture de l'Autre, la contempler, la comprendre et essayer de saisir le monde dans toute sa diversité.

Celina Scheinowitz

Université d'État de Feira de Santana (Brésil)

\section{Naïm Kattan}

L'écrivain migrant. Essais sur des cités et des hommes. Montréal, Hurtubise HMH, coll. "Constantes ", 2001.

Composé de vingt-six courts essais, L'écrivain migrant. Essais sur des cités et des bommes de l'écrivain d'origine irakienne Naïm Kattan propose une réflexion inspirée de l'expérience personnelle de l'auteur sur les questions d'appartenance, d'exil, d'identité, et plus largement, sur l'écriture en tant que mode d'enracinement et de survie.

La première dizaine de textes se compose notamment de commentaires sur les rapports qu'entretient l'écrivain migrant avec la culture et la langue de sa terre d'accueil aussi bien que de son pays natal. Pour Kattan, qui exprime d'emblée son sentiment d'appartenance à Montréal, sa ville d'adoption, " le Haïtien, le Grec, le Brésilien, l'Irakien, le Libanais, 


\section{RECENSIONS}

le Chilien [...] partagent le destin des Québécois, dans la mesure où ils peuvent participer à sa construction. - (p. 19) Si l'écrivain migrant ne renie pas son passé, si sa "mémoire " demeure déterminée par ses origines, il choisira de mêler sa voix *à un chant commun qu'elle enrichit par la diversité . (p. 20) plutôt que de se voir apposer l'étiquette de la marginalité.

Les textes qui suivent se présentent plutôt sous les allures d'un journal de voyages - dont le contenu tend parfois trop vers l'anecdote. Kattan y rend compte de ses séjours dans quelques grandes villes du monde, parmi lesquelles Budapest, Prague, Alger, Jérusalem et Amsterdam, et de ses rencontres avec des écrivains et des personnages influents de la scène politique et culturelle. Ce qu'il faut surtout retenir de ces chroniques à saveur autobiographique est la conclusion à laquelle en vient l'auteur : l'écrivain, quelles que soient ses origines et l'endroit où il choisit de vivre, a la responsabilité de "cerner le réel ", ce qui, admet Kattan, représente une " tâche ardue " (p. 187). La ville devient une métaphore du monde : on surprend l'auteur à rêver à sa ville comme un lieu où ce qu'il appelle la "différence " (p. 190) constituerait une richesse et non un handicap, comme un endroit où les "cloisons " tomberaient enfin si tous acceptaient de s'exprimer et de communiquer dans la langue du milieu (en l'occurrence, en français) et ne se bornaient plus à ne parler que leur langue.

En plus de proposer une réflexion sur l'écriture et sur la façon dont l'écrivain s'adapte à son milieu d'adoption, L'écrivain migrant se donne donc à lire, à certains égards, comme le journal ou les mémoires de l'auteur. On constate à quel point les nombreux séjours qu'il a effectués dans des villes étrangères l'ont marqué, tous pour des raisons qui paraissent à première vue différentes, mais qui somme toute le ramènent à une réalité, voire à une nécessité : celle de l'écriture, de la littérature, de l'importance de la "voix " de l'écrivain et du rôle qu'il est appelé à jouer dans la cité (p. 193). L'écrivain se trouve sans cesse à la recherche du sens, un sens qu'il doit trouver dans le réel pour ensuite le transmettre aux autres, " par la magie des mots * (p. 199), dans l'intimité de la relation qui se développe entre lui et son lecteur. 